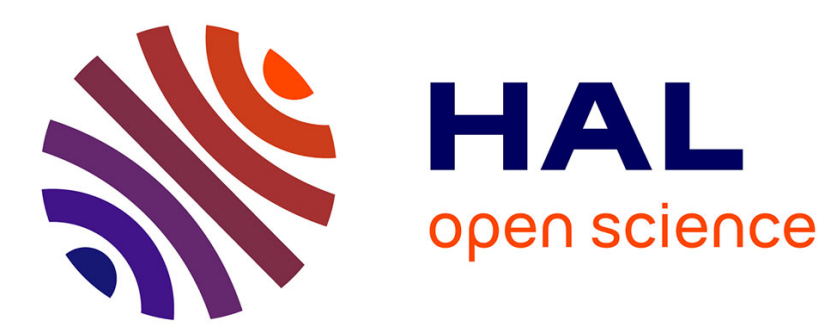

\title{
PAL spectroscopy of rare-earth doped Ga-Ge-Te/Se glasses
}

\author{
Ya. Shpotyuk, A. Ingram, O Shpotyuk
}

\section{To cite this version:}

Ya. Shpotyuk, A. Ingram, O Shpotyuk. PAL spectroscopy of rare-earth doped Ga-Ge-Te/Se glasses. Journal of Physics and Chemistry of Solids, 2016, 91, pp.76-79. 10.1016/j.jpcs.2015.12.010 . hal01254798

\section{HAL Id: hal-01254798 \\ https://hal-univ-rennes1.archives-ouvertes.fr/hal-01254798}

Submitted on 29 Mar 2016

HAL is a multi-disciplinary open access archive for the deposit and dissemination of scientific research documents, whether they are published or not. The documents may come from teaching and research institutions in France or abroad, or from public or private research centers.
L'archive ouverte pluridisciplinaire HAL, est destinée au dépôt et à la diffusion de documents scientifiques de niveau recherche, publiés ou non, émanant des établissements d'enseignement et de recherche français ou étrangers, des laboratoires publics ou privés. 


\author{
PAL spectroscopy of rare-earth doped Ga-Ge-Te/Se glasses \\ Ya. Shpotyuk ${ }^{1,2, *}$, A. Ingram ${ }^{3}$, O. Shpotyuk ${ }^{4,5}$ \\ ${ }^{1}$ Centre for Innovation and Transfer of Natural Sciences and Engineering Knowledge, \\ University of Rzeszow, 1, Pigonia str., 35-959 Rzeszow, Poland \\ ${ }^{2}$ Laboratoire Verres et Céramiques UMR-CNRS 6226, University of Rennes 1, \\ 35042 Rennes Cedex, FRANCE \\ ${ }^{3}$ Institute of Physics, Opole University of Technology, 75, Ozimska str., 45370 Opole, Poland \\ ${ }^{4}$ Vlokh Institute of Physical Optics, 23, Dragomanov str., 79005 Lviv, Ukraine \\ ${ }^{5}$ Institute of Physics, Jan Dlugosz University, 13/15, Armii Krajowej al., 42200 Czestochowa, Poland \\ *The corresponding author e-mail: yashpotyuk@gmail.com
}

\begin{abstract}
Positron annihilation lifetime (PAL) spectroscopy was applied for the first time to study freevolume void evolution in chalcogenide glasses of Ga-Ge-Te/Se cut-section exemplified by glassy $\mathrm{Ga}_{10} \mathrm{Ge}_{15} \mathrm{Te}_{75}$ and $\mathrm{Ga}_{10} \mathrm{Ge}_{15} \mathrm{Te}_{72} \mathrm{Se}_{3}$ doped with $500 \mathrm{ppm}$ of $\mathrm{Tb}^{3+}$ or $\mathrm{Pr}^{3+}$. The collected PAL spectra reconstructed within two-state trapping model reveal decaying tendency in positron trapping efficiency in these glasses under rare-earth doping. This effect results in unchanged or slightly increased defectrelated lifetimes $\tau_{2}$ at the cost of more strong decrease in $I_{2}$ intensities, as well as reduced positron trapping rate in defects and fraction of trapped positrons. Observed changes are ascribed to rare-earth activated elimination of intrinsic free volumes associated mainly with negatively-charged states of chalcogen atoms especially those neighboring with Ga-based polyhedrons.
\end{abstract}

Keywords: chalcogenides; glasses, positron annihilation spectroscopy, defects, microstructure

\title{
Introduction
}

Chalcogenide glasses $(\mathrm{ChG})$, e.g. chemical compounds of chalcogens ( $\mathrm{S}, \mathrm{Se}$ or Te, but not $\mathrm{O}$ ) with some elements from IV-V groups of the Periodic table quenched from a melt state, have found widespread application in modern chalcogenide photonics [1] because of their superior transmittance in IR spectral region including both atmospheric (3-5 $\mu \mathrm{m}$ and 8-12 $\mu \mathrm{m})$ and space telecommunication windows [2-4]. In general, this remarkable feature is caused by high-phonon frequencies typical for chalcogenide-like environment essentially overcome those in oxide media. This functionality can be further stretched by doping ChG with some rare-earth (RE) activators like $\mathrm{Pr}^{3+}, \mathrm{Tb}^{3+}, \mathrm{Dy}^{3+}, \mathrm{Er}^{3+}$, etc., which possess numerous radiative transitions emitting in near and mid-IR range up to $10 \mu \mathrm{m}$ thus providing advanced optical fibers for this spectral domain [5-7]. However, because of very low solubility in chalcogenide compounds [8-9], the ChG should be essentially modified to accommodate 
RE ions in electrically active functional state allowing light generation. As a rule, it can be achieved only in ChG modified by such codopants as Ga or In, which possess unique ability of charge compensation for guest RE ions embedded in host ChG matrix [5,8-12]. In fact, this effect is realized owing to complicated structural changes, stretching over both atomic-specific and atomic-deficient levels, where intrinsic free-volume elements of low-electron densities (vacancies and vacancy-like clusters, their agglomerates, voids, etc.) play an important role [13-15].

This work is aimed to recognize how these structural changes in RE-doped ChG possessing a relatively high content of $\mathrm{Ga}$ additions will be accessible (if any) for positron annihilation lifetime (PAL) spectroscopy, a high-informative tool successfully applied recently to identify sub-atomistic free volumes in many glass-forming media [15-19].

\section{Experimental}

Two Ga-contained ChG of Ga-Ge-Te/Se cut-section doped with $500 \mathrm{ppm}$ of $\mathrm{Tb}^{3+}$ were tested with PAL spectroscopy, they being $\mathrm{Ga}_{10} \mathrm{Ge}_{15} \mathrm{Te}_{75}$ (one of most stable glassy alloy in Ga-Ge-Te system [20]) and $\mathrm{Ga}_{10} \mathrm{Ge}_{15} \mathrm{Te}_{72} \mathrm{Se}_{3}$, where some amount of Se was introduced instead of Te to form glassy alloy more stable against crystallization [21]. In the latter case, we also used the $\operatorname{Pr}^{3+}$ ions as doping agents in the same content $(500 \mathrm{ppm})$. The glassy samples were prepared by conventional meltquenching route using high-purity commercial elemental precursors Ga $(7 \mathrm{~N})$, Se (5N), Te (6N), Ge $(5 \mathrm{~N}), \mathrm{Pr}_{2} \mathrm{Se}_{3}(3 \mathrm{~N})$ and $\mathrm{Tb}_{2} \mathrm{Se}_{3}(3 \mathrm{~N})$. The appropriate amounts of initial elements with total weight of 25-30 $\mathrm{g}$ were inserted into a silica tube of $10 \mathrm{~mm}$ in a diameter. The ampoules were sealed under a vacuum and heated to $950^{\circ} \mathrm{C}$ in a rocking furnace for $1 \mathrm{~h}$, after they were cooled down to $900^{\circ} \mathrm{C}$ for 10 $\mathrm{h}$ homogenization followed by quenching into room-temperature water from $700^{\circ} \mathrm{C}$. To remove mechanical strains caused by rapid quenching, the $\mathrm{ChG}$ samples were annealed during $5 \mathrm{~h}$ at $10^{\circ} \mathrm{C}$ below glass transition temperature. The obtained rods were cut into disks of $\sim 2 \mathrm{~mm}$ in thickness and polished to a high optical quality.

The prepared ChG samples were in a glassy form as it followed from absence of any sharp crystalline peaks in X-ray diffraction (XRD) patterns demonstrating only stretched amorphous halos and characteristic coinchoidal fracture on fresh cut-sections. No significant changes between optical properties of un-doped and RE-doped ChG were observed, apart from slight long-wave shift in optical transmission edge due to RE absorption close to $2 \mu \mathrm{m}$ and absorption bands of $\mathrm{Tb}^{3+}$ at 2.95 and 4.75 $\mu \mathrm{m}$ (transitions from ground ${ }^{7} \mathrm{~F}_{6}$ state to ${ }^{7} \mathrm{~F}_{4}$ and ${ }^{7} \mathrm{~F}_{5}$ levels, respectively) and $\mathrm{Pr}^{3+}$ at 2.05 and $4.50 \mu \mathrm{m}$ (transitions from ground ${ }^{3} \mathrm{H}_{4}$ state to ${ }^{3} \mathrm{~F}_{2}$ and ${ }^{3} \mathrm{H}_{5}$ levels, respectively) [9].

The PAL spectra were registered using fast coincidence system ORTEC of 230 ps resolution (the full width at half maximum) operated at high-stabilized normal measuring conditions (an ambient temperature of $22^{\circ} \mathrm{C}$ and relative humidity of $35 \%$ ). The pairs of identical plane-parallel samples of each composition in typical sandwich geometry (covering ${ }^{22} \mathrm{Na}$ isotope of slow $\sim 50 \mathrm{kBq}$ activity) were 
employed, the contribution from a source being taken at the level of $12 \%(\tau=0.352 \mathrm{~ns})$. To ensure reliable PAL data, three independent measuring cycles each covering nearly $1 \mathrm{M}$ elementary positron annihilation events were performed. The experimental results were fitted by two single exponents under normalized intensities $\left(I_{1}+I_{2}=1\right)$ using LT 9.0 program [22]. Introducing third component to fitting curve did not improve decomposition goodness significantly, the estimated input from this longlived component in the PAL spectra being less than $1 \%$. Fitting uncertainties in positron lifetimes $\tau_{1,2}$ and component intensities $I_{1,2}$ were at the level of $\pm(0.0020-0.0040)$ ns and $\pm(0.0030-0.0050)$, respectively. This provides a reliable final error-bar for such ex-situ measuring protocol not worse than $\pm 0.005 \mathrm{~ns}$ in lifetimes $\tau_{1,2}$ and $\pm 0.5 \%$ in intensities $I_{1,2}$. Mathematical formalism of known two-state trapping model with only one kind of positron traps [23-27] was utilized to parameterize mean $\tau_{a v}$ and defect-free bulk $\tau_{b}$ lifetimes, as well as trapping rate in defects $\kappa_{d}$. The difference between defectrelated $\tau_{d}=\tau_{2}$ and bulk positron lifetimes $\left(\tau_{2}-\tau_{b}\right)$ was taken as a signature of size of positron traps in terms of equivalent number of vacancies, while $\tau_{2} / \tau_{\mathbf{b}}$ ratio was ascribed to the nature of these defects [23]. The fraction of trapped positrons $\eta=\tau_{1} \cdot \kappa_{d}$ participating in an annihilation was also controlled.

\section{Results and Discussion}

The typical raw PAL spectra of the studied glassy $\mathrm{Ga}_{10} \mathrm{Ge}_{15} \mathrm{Te}_{75}$ samples, both un-doped and $\mathrm{Tb}^{3+}$-doped ones, reconstructed from two-component fitting at the general background of standard source contribution are shown in Fig. 1a and 1b, respectively (the similar spectra were collected for other glassy alloys). These PAL spectra as typical histograms of elementary positron annihilation events are characterized by narrow peaks and regions of long fluent decaying of coincidence counts in a time. The limited values of statistical scatter of variance compactly grouped around 0-axis testify that PAL measurements were adequately described by this fitting procedure. Thus, the decaying behavior of such curve can be represented by sum of separate exponents with different time constants inversed to positron lifetimes [23-25].

The best-fit positron trapping parameters of the studied ChG calculated within two-state model [23-27] are given in Table 1. The parent $\mathrm{Ga}_{10} \mathrm{Ge}_{15} \mathrm{Te}_{75}$ glass is characterized by quite high defectrelated positron lifetime $\tau_{2}=0.365 \mathrm{~ns}$ and moderate intensity $I_{2}=0.43$ reflecting positron trapping in relatively stretched free-volume defects such as multiatomic vacancy clusters [28]. With 3 at. \% of Se substituted Te to produce $\mathrm{Ga}_{10} \mathrm{Ge}_{15} \mathrm{Te}_{72} \mathrm{Se}_{3}$ glass, the positron trapping attains features character for more fragmented void structure [27]. The $\tau_{2}$ lifetime slightly decreases to $0.346 \mathrm{~ns}$, while $I_{2}$ intensity shows more noticeable growing tendency to 0.52 , thus resulting in more than five-times enhanced trapping rate in free-volume defects in $\mathrm{Ga}_{10} \mathrm{Ge}_{15} \mathrm{Te}_{72} \mathrm{Se}_{3}$ glass.

It is evidently seen from Fig. 1 that RE doping does not change essentially mass-center position of all positron annihilation events $\tau_{a v}$, as well as characteristic non-defect bulk positron lifetimes $\tau_{b}$ of both $\mathrm{Ga}_{10} \mathrm{Ge}_{15} \mathrm{Te}_{75}$ and $\mathrm{Ga}_{10} \mathrm{Ge}_{15} \mathrm{Te}_{72} \mathrm{Se}_{3} \mathrm{ChG}$, since all changes are within statistical error-bar of 
positron lifetimes determination (see Table 1). Under a such condition, the physically realistic meaning ACCEPTED MANUSCPRPT

attains only second component in the reconstructed PAL spectrum, the corresponding $\tau_{2}$ lifetime reflecting low-electron density volumes where positrons are trapped and $I_{2}$ intensity being proportional to concentration of these traps [23]. The defect-related positron lifetime $\tau_{2}$ does not change with $\mathrm{Tb}^{3+}$ doping in $\mathrm{Ga}_{10} \mathrm{Ge}_{15} \mathrm{Te}_{75} \mathrm{ChG}$ ( $\tau_{2}=0.365 \mathrm{~ns}$ ), but rather only slightly grows in partially Se-substituted glassy $\mathrm{Ga}_{10} \mathrm{Ge}_{15} \mathrm{Te}_{72} \mathrm{Se}_{3}$ alloy (Table 1). The most essential growing effect in $\tau_{2}$ lifetime from $0.346 \mathrm{~ns}$ to $0.356 \mathrm{~ns}$ is also caused in this $\mathrm{Ga}_{10} \mathrm{Ge}_{15} \mathrm{Te}_{72} \mathrm{Se}_{3} \mathrm{ChG}$ affected by $\mathrm{Pr}^{3+}$ additions. At the same time, the RE doping is accompanied by considerable decrease in the $I_{2}$ intensity in both glassy $\mathrm{Ga}_{10} \mathrm{Ge}_{15} \mathrm{Te}_{75}$ and $\mathrm{Ga}_{10} \mathrm{Ge}_{15} \mathrm{Te}_{72} \mathrm{Se}_{3}$, this effect reaching as high as $6 \%$ in case of $\mathrm{Tb}^{3+}$-doped $\mathrm{Ga}_{10} \mathrm{Ge}_{15} \mathrm{Te}_{72} \mathrm{Se}_{3}$ glass.

Thus, the observed changes in the fitting parameters describing the reconstructed PAL-spectra correspond to obvious decaying tendency in positron trapping efficiency in the studied ChG under RE doping. This effect results in the reduction of trapping rate in defects $\kappa_{d}$ and fraction of trapped positrons $\eta$ (Table 1). Let's clarify physical meaning of this process and give its possible explanation in terms of known microstructure models developed for positron trapping in ChG [17,28-34].

It is known that positrons are captured in the $\mathrm{ChG}$ by extended free-volume defects localized in a vicinity of chalcogen $(\mathrm{Ch})$ atoms [17,29-31]. Such positron traps are formed by atomic-accessible cores of geometrical free volumes surrounded by atomic-inaccessible shell of overlapped bond-free solid angles (BFSA), e.g. low-electron density spaces appeared due to directionality of covalent chemical bonds around $\mathrm{Ch}$ atoms in a glassy network [35]. In homoatomic ChG like Se or Ch-rich $\mathrm{As} / \mathrm{Ge}-\mathrm{Se} / \mathrm{Te}$ glasses, the neutral $\mathrm{Ch}_{2}{ }^{0}$ states (the sub- and super-script stays for local coordination and electrical charge, respectively) are mostly dominant in the overall balance of positron trapping events, since As/Ge-related traps are rather ineffective in view of their repulsive potential to positrons [31]. However, in heteroatomic $\mathrm{ChG}$ like glassy As/Ge-Ch alloys close to stoichiometry, the positron trapping prevails on free-volume defects surrounded by overlapped BFSA, which are localized in the bottom of main glass-forming structural units (trigonal $\mathrm{AsCh}_{3 / 2}$ pyramids and tetragonal $\mathrm{GeCh}_{4 / 2}$ tetrahedrons). Because of significant difference in the electronegativity of anion-type Ch and cationtype As/Ge atoms [36], such defects related to local $\mathrm{Ch}_{2}{ }^{-}$configurations can be imagined as prototypes of negatively-charged vacancies like cation vacancies in crystalline counterparts of these compounds $[23,37]$. Correspondingly, the defect-related positron annihilation lifetimes $\tau_{d}=\tau_{2}$ grow with going from glassy Se (with positron traps having preferential neutral $\mathrm{Ch}_{2}{ }^{0}$-type shell within homoatomic chainand ring-like configurations) to stoichiometric $\mathrm{As}_{2} \mathrm{Ch}_{3}$ (with positron traps having preferential $\mathrm{Ch}_{2}{ }^{-}$ type shell in the bottom of $\mathrm{AsCh}_{3 / 2}$ pyramids or $\mathrm{GeCh}_{4 / 2}$ tetrahedrons), showing an obvious anomaly in respect to compositional trend in a molar volume, as it was proved experimentally [31].

To be functional in $\mathrm{ChG}$, the RE dopants should occupy an active " $3+$ " state $\left(\mathrm{Tb}^{3+}\right.$ or $\left.\operatorname{Pr}^{3+}\right)$. Under a condition of global electroneutrality proper to full saturation of covalent bonding in ChG networks (in respect to known $8-N$ rule [38]), this demands local inhomogeneities possessing an 
effective negative charge to compensate an excess of positive electrical charge of embedded RE ions. Such inhomogeneities can be produced owing to incorporation of $\mathrm{Ga}$ (or alternatively In) in ChG without disturbing their glass-forming ability [8,9]. As typical metallic atoms, the Ga dopants tend to saturate their highest local coordination in respect to Ch-environment (predominantly tetrahedral coordination in glassy Ga-Ge-Te system [10,11,39-41], obviously overcoming a full saturation of covalent chemical bonding of un-doped $\mathrm{ChG}$ matrix [8]. Thus, some $\mathrm{Ch}$ atoms occur to be poorly linked with $\mathrm{Ga}$ (approaching $\mathrm{Ch}^{2-}$ state), ensuring an excess of compensating negative charge for embedded RE ions. In other words, to satisfy a condition of global charge compensation within a whole glassy matrix, the positively charged RE ions act as charge-balancing cations in respect to negatively charged $\mathrm{Ch}$ ions linked with Ga additions.

Thus, a complicated network of cycle-type formations built of Ge- and Ga-based polyhedrons (tetrahedra) showing a character topology of atomic-deficient free-volume voids is stabilized in glassy $\mathrm{Ga}_{10} \mathrm{Ge}_{15} \mathrm{Te}_{75}$ and $\mathrm{Ga}_{10} \mathrm{Ge}_{15} \mathrm{Te}_{72} \mathrm{Se}_{3}$. Under a random distribution and high enough content (10 mol. \%), the Ga-based tetrahedra contribute to a majority of such voids, thus enhancing positron trapping efficiency in these ChG. However, because of overall negative charge, just these free-volume voids are also effective attractors for RE dopants. So under RE doping, these voids occupied by $\mathrm{Tb}^{3+}$ and $\operatorname{Pr}^{3+}$ ions (through Ga-Te-RE linkages [8]) are subsequently eliminated as potential positron trapping sites. Therefore, in all cases of RE doping, the intensities of defect-related component $I_{2}$ in the reconstructed PAL spectra are sharply inhibited (see Table 1). Since all free-volume voids accommodated Ga-based tetrahedrons equally participate in this process, there are no essential shift in the averaged values of defect-related positron lifetimes $\tau_{2}$, which is in good harmony with our experimental data in Table 1 .

\section{Conclusions}

The PAL spectroscopy was applied to study free-volume void evolution in glassy $\mathrm{Ga}_{10} \mathrm{Ge}_{15} \mathrm{Te}_{75}$ and $\mathrm{Ga}_{10} \mathrm{Ge}_{15} \mathrm{Te}_{72} \mathrm{Se}_{3}$ alloys affected by doping with $500 \mathrm{ppm}$ of $\mathrm{Tb}^{3+}$ or $\mathrm{Pr}^{3+}$ ions. Within two-state positron trapping model, the principal effect of doping is revealed as conserving and slight increase in defect-related positron lifetimes $\tau_{2}$ at the cost of essentially reduced $I_{2}$ intensities. The corresponding changes in positron trapping modes extracted from two-component reconstructed experimental PAL spectra are ascribed to RE activated elimination of intrinsic free-volume voids associated mainly with negatively-charged states of chalcogen atoms neighboring with Ga-based polyhedrons.

\section{Acknowledgement}

ShYa acknowledges support for this research funded by Marie-Curie Action FP7-PEOPLE2010-ITN under the GlaCERCo project. 


\section{References}

1. B.J. Eggleton, B. Luther-Davies, K. Richardson, Nature Photon. 5 (2011) 141-148.

2. J.-L. Adam, X. Zhang (Eds.), Chalcogenide Glasses: Preparation, Properties and Applications, Woodhead Publishing, Oxford, Cambridge, New Dehli, 2014.

3. S. Cui, R. Chahal, Ya. Shpotyuk, C. Boussard, J. Lucas, F. Charpentier, H. Tariel, O. Loreal, V. Nazabal, O. Sire, V. Monbet, Z. Yang, P. Lucas, B. Bureau, Proc. SPIE 8938 (2014) 893805-1-9.

4. B. Bureau, X. Zhang, F. Smektala, J.-L. Adam, J. Troles, H. Ma, C. Boussard-Pledel, J. Lucas, P. Lucas, D. Le Coq, M.R. Riley, J.H. Simmons, J. Non-Cryst. Solids 345-346 (2004) 276-283.

5. A.B. Seddon, Z. Tang, D. Furniss, S. Sujecki, T.M. Benson, Opt. Express 18 (2010) 26704.

6. B. Cole, L.B. Shaw, P.C. Pureza, R. Mossadegh, J.S. Sanghera, I.D. Aggarwal, J. Non-Cryst. Solids 256-257 (1999) 253-259.

7. J. Hu, C.R. Menyuk, C. Wei, B. Shaw, J.S. Sanghera, I.D. Aggarwal, Opt. Lett 40 (2015) 36873690 .

8. B.G. Aitken, C.W. Ponader, R.S. Quimby, C.R. Chimie 5 (2002) 865-872.

9. M.F. Churbanov, I.V. Scribachev, V.S. Shiryaev, V.G. Plotnichenko, S.V. Smetanin, E.B. Kryukova, Yu.N. Pyrkov, B.I. Galagan, J. Non-Cryst. Sol. 326-327 (2013) 301-305.

10. R. Golovchak, Ya. Shpotyuk, V. Nazabal, C. Boussard-Pledel, B. Bureau, J. Cebulski, H. Jain, J. Chem. Phys. 142 (2015) 184501-1-10.

11. Ya. Shpotyuk, B. Bureau, C. Boussard-Pledel, V. Nazabal, R. Golovchak, P. Demchenko, I. Polovynko, J. Non-Cryst. Solids 398-399 (2014) 19-25.

12. Ya. Shpotyuk, C. Boussard-Pledel, V. Nazabal, R. Chahal, J. Ari, B. Pavlyk, J. Cebulski, J.L. Doualan, B. Bureau, Opt. Mater. 46 (2015) 228-232.

13. Z. Tang, N.C. Neate, D. Furniss, S. Sujecki, T.M. Benson, A.B. Seddon, J. Non-Cryst. Solids 357 (2011) 2453-2462.

14. C. Liu, G. Tang, L. Luo, W. Chen, J. Am. Ceram. Soc. 92 (2009) 245-248.

15. O. Shpotyuk, A. Ingram, B. Bureau, Ya. Shpotyuk, C. Boussard-Pledel, V. Nazabal, R. Szatanik, J. Phys. Chem. Solids 75 (2014) 1049-1053.

16. O. Shpotyuk, L. Calvez, E. Petracovschi, H. Klym, A. Ingram, P. Demchenko, J. Alloys Compd. 582 (2014) 323-327.

17. O. Shpotyuk, J. Filipecki, Free volume in vitreous chalcogenide semiconductors: possibilities of positron annihilation lifetime study, Ed. WSP, Czestochowa, 2003.

18. B. Jasinska, A.L. Dawidowicz, T. Goworek, S. Radkiewicz, Phys. Chem. Chem. Phys. 2 (2000) 3269-3274.

19. V.P. Shantarovich, J. Polym. Sci., Part B: Polym. Phys. 46 (2008) 2485-2503.

20. S. Danto, P. Houizot, C. Boussard-pledel, X. Zhang, F. Smektala, J. Lucas, Adv. Funct. Mater. 16 (2006) 1847-1852. 
21. B. Bureau, C, Boussard-Pledel, P. Lucas, X. Zhang, J. Lucas, Molecules 14 (2009) 4337-4350.

22. J. Kansy, Nucl. Instrum. Methods Phys. Res., Sect. A 374 (1996) 235.

23. R. Krause-Rehberg, H. Leipner, Positron annihilation in semiconductors: defect studies, Springer, Heidelberg; 1999.

24. D.J. Keeble, U. Brossmann, W. Puff, R. Würschum, in: E.N. Kaufmann (Ed.), Characterization of materials, John Wiley \& Sons, Inc.; 2012, pp. 1899-1925.

25. F. Tuomisto, I. Makkonen, Rev. Mod. Phys. 85 (2013) 1583-1631.

26. A. Seeger, Appl. Phys. 4 (1974) 183-199.

27. M. Shpotyuk, A. Ingram, O. Shpotyuk, J. Mater. Res. 30 (2015) 1422-1429.

28. K.O. Jensen, P.S. Salmon, I.T. Penfold, P.G. Coleman, J. Non-Cryst. Solids 170 (1994) 57-64.

29. M. Hyla, J. Filipecki, O. Shpotyuk, M. Popescu, V. Balitska, J. Optoelectron. Adv. Mat. 9 (2007) 3177-3181.

30. O.I. Shpotyuk, J. Filipecki, V.O. Balitska, J. Optoelectron. Adv. Mat. 10 (2008) 3193-3197.

31. A. Ingram, R. Golovchak, M. Kostrzewa, S. Wacke, M. Shpotyuk, O. Shpotyuk, Phys. B 407 (2012) 652-655.

32. O. Shpotyuk, R. Golovchak, A. Ingram, V. Boyko, L. Shpotyuk, Phys. Status Solidi C 10 (2013) 117-120.

33. O. Shpotyuk, J. Filipecki, M. Shpotyuk, A. Ingram, Solid State Ionics 267 (2014) 38-43.

34. O. Shpotyuk, A. Ingram, M. Shpotyuk, J. Filipecki, Nucl. Instrum. Methods Phys. Res., Sect. B 338 (2014) 66-71.

35. M. Kastner, Phys. Rev. B 7 (1973) 5237-5252.

36. L. Pauling, The nature of the chemical bond, Cornell Univ. Press., Ithaca, 1960.

37. R. Krause-Rehberg, H.S. Leipner, T. Algarjan, A. Polity, Appl. Phys. A 66 (1998) 599-614.

38. A. Feltz, Amorphous and vitreous inorganic solids, Mir, Moscow, 1986.

39. P. Jovari, I. Kaban, B. Bureau, A. Wilhelm, P. Lucas, B. Beuneu, D.A. Zajac, J. Phys. Condens. Matter 22 (2010) 404207-1-404207-9

40. I. Voleska, J. Akola, P. Joovari, J. Gutwirth, T. Wagner, Th. Vasileiadis, S.N. Yannopoulos, R.O. Jones, Phys. Rev. B 86 (2012) 094108-1-094108-9.

41. R. Golovchak, L. Calvez, B. Bureau, H. Jain, J. Chem. Phys. 139 (2013) 054508-1-054508-9. 


\section{ACCEPTED MANUSCRIPT}

Table 1. Fitting parameters and positron trapping modes describing two-component reconstructed PAL spectra of RE-doped ChG alloys

\begin{tabular}{|c|c|c|c|c|c|c|c|c|c|}
\hline \multirow{3}{*}{$\begin{array}{l}\text { Glass composition, } \\
\text { RE doping ions }\end{array}$} & \multicolumn{3}{|c|}{ Fitting parameters } & \multicolumn{6}{|c|}{ Positron trapping modes } \\
\hline & $\tau_{1}$ & $\tau_{2}$ & $I_{2}$ & $\tau_{a v .}$ & $\tau_{b}$ & $\kappa_{d}$ & $\tau_{2}-\tau_{b}$ & $\tau_{2} / \tau_{b}$ & $\eta$ \\
\hline & ns & ns & a.u. & ns & ns & $\mathrm{ns}^{-1}$ & ns & - & - \\
\hline $\mathrm{Ga}_{10} \mathrm{Ge}_{15} \mathrm{Te}_{75}$ & 0.211 & 0.365 & 0.431 & 0.277 & 0.258 & 0.86 & 0.11 & 1.41 & 0.18 \\
\hline $\begin{array}{l}\mathrm{Ga}_{10} \mathrm{Ge}_{15} \mathrm{Te}_{75} \\
+500 \mathrm{ppm} \mathrm{Tb}^{-} \mathrm{Tb}\end{array}$ & 0.207 & 0.364 & 0.401 & 0.270 & 0.251 & 0.83 & 0.11 & 1.45 & 0.17 \\
\hline $\mathrm{Ga}_{10} \mathrm{Ge}_{15} \mathrm{Te}_{72} \mathrm{Se}_{3}$ & 0.197 & 0.346 & 0.520 & 0.275 & 0.254 & 1.13 & 0.09 & 1.36 & 0.22 \\
\hline $\begin{array}{l}\mathrm{Ga}_{10} \mathrm{Ge}_{15} \mathrm{Te}_{72} \mathrm{Se}_{3} \\
+500 \mathrm{ppm} \mathrm{Tb}\end{array}$ & 0.200 & 0.350 & 0.463 & 0.270 & 0.250 & 0.99 & 0.10 & 1.40 & 0.20 \\
\hline $\begin{array}{l}\mathrm{Ga}_{10} \mathrm{Ge}_{15} \mathrm{Te}_{72} \mathrm{Se}_{3} \\
+500 \mathrm{ppm} \mathrm{Pr}\end{array}$ & 0.203 & 0.356 & 0.481 & 0.277 & 0.256 & 1.02 & 0.10 & 1.39 & 0.21 \\
\hline
\end{tabular}
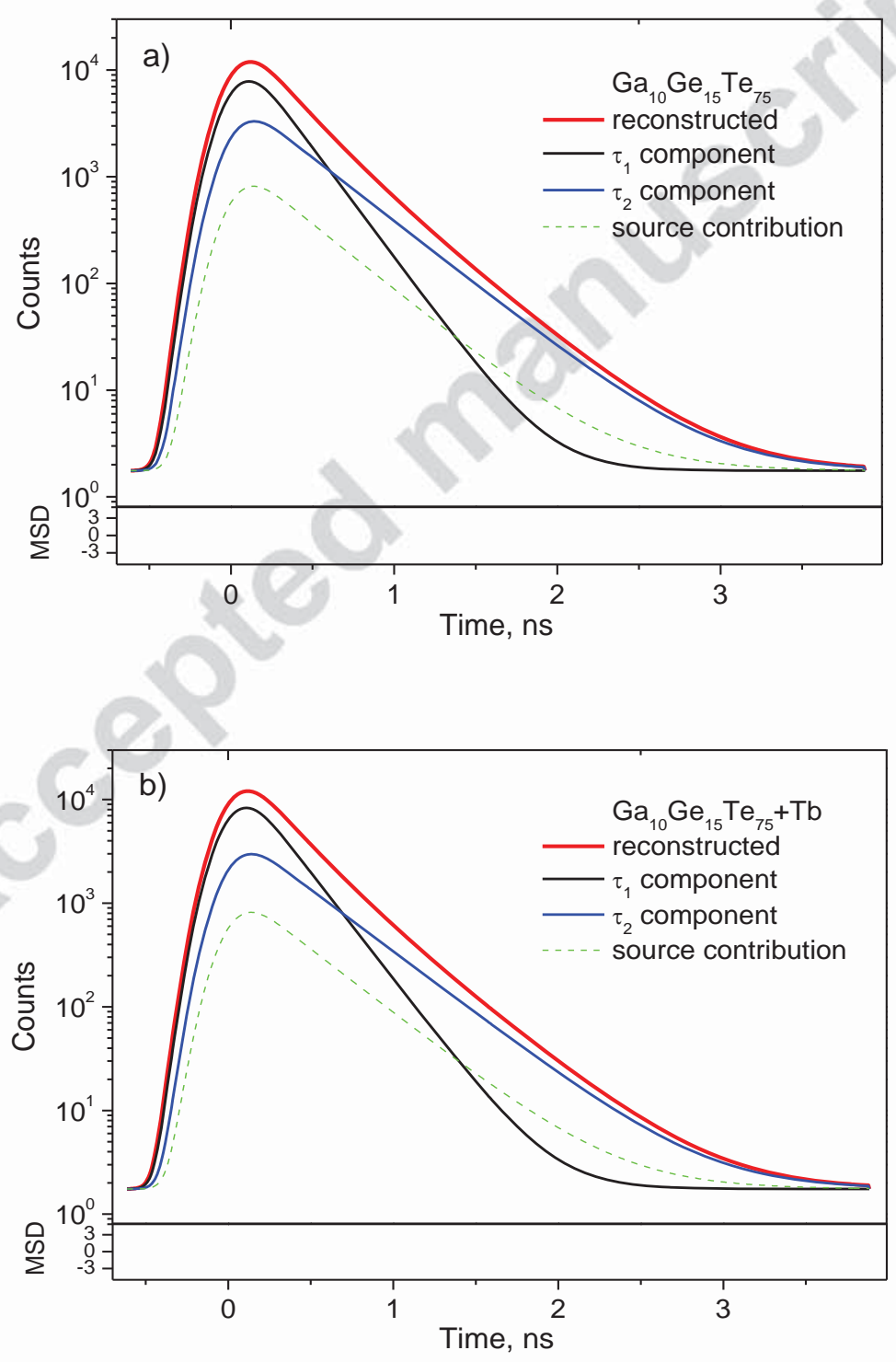
Fig. 1. Raw PAL spectra of ChG reconstructed from two-component fitting at the general background of source contribution: $\mathrm{a}-\mathrm{Ga}_{10} \mathrm{Ge}_{15} \mathrm{Te}_{75} ; \mathrm{b}-\mathrm{Ga}_{10} \mathrm{Ge}_{15} \mathrm{Te}_{75}$ doped with $500 \mathrm{ppm}$ of $\mathrm{Tb}^{3+}$ (bottom inset shows statistical scatter of variance).

\section{Highlights:}

Positron annihilation spectroscopy to study rare-earth doping in Ga-Ge-Te/Se glasses Two-state trapping model to reconstruct experimental positron lifetime spectra Decaying tendency in positron trapping efficiency in glasses under rare-earth doping Rare-earth activated elimination of free-volume voids associated with Ga-tetrahedrons 